\title{
INVESTIGATION OF A TRIPROPYLENE-GLYCOL MONOMETHYL ETHER AND DIESEL BLEND FOR SOOT-FREE COMBUSTION IN AN OPTICAL DIRECT-INJECTION DIESEL ENGINE
}

\author{
Cosmin E. Dumitrescu ${ }^{+, \dagger}$, Charles J. Mueller*, Eric Kurtz ${ }^{\S}$ \\ ${ }^{+}$West Virginia University, 275 Eng. Sci. Bldg., Morgantown, WV 26506, USA \\ *Sandia National Laboratories, 7011 East Avenue, Livermore, CA 94550, USA \\ ${ }^{\S}$ Ford Motor Co., 1 American Rd., Dearborn, MI 48126, USA
}

\begin{abstract}
Natural luminosity and chemiluminescence imaging diagnostics were employed to investigate if a 50/50 blend by volume of tripropylene-glycol monomethyl ether (TPGME) and ultra-low sulfur \#2 diesel certification fuel (CF) could enable leaner-lifted flame combustion (LLFC), a non-sooting mode of mixing-controlled combustion associated with equivalence ratios below approximately 2 . The experiments were performed in a singlecylinder heavy-duty optical compression-ignition engine at three injection pressures and three dilution levels. Results indicate that TPGME addition effectively eliminated engine-out smoke emissions by curtailing soot production and/or increasing soot oxidation during and after the end of fuel injection. TPGME greatly reduced soot luminosity when compared with neat $C F$, but did not enable LLFC because the equivalence ratios at the lift-off length, $\phi(H)$, never reached the non-sooting limit and incandescence from hot soot within the combustion chambered remained visible. Concerning other engine-out emissions, injection pressure influenced the effects of TPGME addition on $\mathrm{NO}_{\mathrm{x}}$ emissions. $\mathrm{HC}$ and $\mathrm{CO}$ emissions were higher compared to the baseline fuel, likely due to the lower net heat of combustion of TPGME and the need to limit fuel-injection duration for valid optical measurements.
\end{abstract}

Keywords: Diesel, Soot-free combustion, Oxygenate, LLFC.

\section{INTRODUCTION}

Diesel engines have higher fuel-conversion efficiencies and lower $\mathrm{CO}_{2}$ emissions compared to spark-ignition gasoline engines, but still produce $\mathrm{NO}_{\mathrm{x}}$ and particulate matter (PM, of which a significant fraction is typically soot) that require expensive aftertreatment systems to achieve compliance with emission regulations in most developed nations. Advanced combustion strategies can lower $\mathrm{NO}_{\mathrm{x}}$ and PM emissions [1-4], but are not yet broadly applicable at high load where diesel combustion is mixing-controlled. A particular form of mixing-controlled diesel combustion, leaner lifted-flame combustion (LLFC) can eliminate soot if the equivalence ratio at the flame lift-off location (defined as the axial distance between the fuel injector orifice exit and the position where the standing premixed autoignition zone stabilizes during mixing-controlled combustion [5]) is less than two [6,7]. With conventional diesel fuel, LLFC was obtained at an injection duration typical of moderate-load engine operating conditions using high fuel-injection pressures (240 MPa), low intake temperatures, retarded combustion timings, and moderate exhaust-gas recirculation (EGR) rates, but only with a 2-hole injector tip [7]. A strategy to increase LLFC applicability to higher engine loads is to use oxygenated fuels, which have been shown to curtail soot emissions due to the presence of oxygen in the fuel molecule [8-13]. The optimum oxygenated fuel would be compatible with existing distribution infrastructure and compression-ignition engines, and exhibit the same or improved properties, e.g., viscosity, cetane number $(\mathrm{CN})$, lubricity, corrosivity, elastomer compatibility, toxicity, and cost per unit 
of chemical energy relative to conventional diesel fuel. Natarajan et al. [8] evaluated a total of 71 potential oxygenate candidates considered the most suitable for blending with diesel for further engine testing and found notable differences in their effects on diesel combustion due to diversity in chemical structure (e.g., number and locations of oxygen atoms, types and sizes of hydrocarbon moieties, molecular weight). Gonzalez et al. [9] tested the eight selected oxygenated fuels in [8] in a light-duty diesel engine. They found that tripropylene-glycol monomethyl ether (TPGME, $\mathrm{C}_{10} \mathrm{H}_{22} \mathrm{O}_{4}$ ) and dibutyl maleate (DBM, $\mathrm{C}_{12} \mathrm{H}_{20} \mathrm{O}_{4}$ ) were the most promising candidate oxygenate compounds for future engine testing based on total PM emissions and other considerations, like other gaseous emissions (i.e., $\mathrm{NO}_{\mathrm{x}}, \mathrm{HC}$, and $\mathrm{CO}$ emissions), flash point, and toxicity. Mueller et al. [10] tested DBM and TPGME in a constant-volume combustion vessel and a single-cylinder DI diesel engine, each with extensive optical access. They found that fuels containing TPGME are more effective at lowering soot levels than those containing DBM. The reason is the efficient usage of the $\mathrm{O}$ atoms present in the TPGME. The particular distribution of $\mathrm{O}$ atoms in the TPGME molecule ensures that each $\mathrm{O}$ atom leads to a $\mathrm{CO}$ molecule, thus preventing a greater fraction of the $\mathrm{C}$ atoms from contributing to the pool of available soot precursor species [10, 14].

Ignition delay and flame lift-off length are two important parameters for combustion control and stability under LLFC conditions. A longer ignition delay can increase unburned hydrocarbon emissions if it results in over-mixing (i.e., areas of fuel-air mixtures below the flammability limit) $[15,16]$ and noise if it results in higher rates of pressure change $[17,18]$, while a longer lift-off length can raise the probability of ignition products being affected by the piston or chamber walls $[19,20]$. As a result, it would be beneficial for the oxygenated fuel to have a similar ignition delay and lift-off length as the diesel fuel. Manin et al. [12], which compared various oxygenated fuels, alkanes, and their blends, found no noticeable impact on ignition delay and a minor effect on lift-off length when TPGME was blended with an alkane of similar cetane number (like n-hexadecane). TPGME has a higher cetane rating than typical diesel fuels $[8,21]$, therefore it is expected that TPGME would have similar or shorter ignition delay and lift-off length than diesel fuel.

The objective of the current study is to determine if a 50/50 blend by volume of TPGME with a \#2 ultra-low sulfur diesel baseline fuel (the blend called T50) could enable LLFC at a lower fuel-injection pressure and in-cylinder dilution compared with the neat baseline fuel. Specific goals include identifying the extent to which T50 can enable sustained LLFC by reducing the fuel-air equivalence ratios in combustion regions where soot formation would otherwise occur. Experiments were conducted at three fuel-injection pressures with three levels of charge-gas dilution. Diagnostics include conventional heat-release analysis, engineout emissions, and high-speed in-cylinder imaging of both natural luminosity and $\mathrm{OH}$ chemiluminescence. Ultimately, the experimental results are used to obtain an improved understanding of the extent to which TPGME can reduce engine-out emissions without additional changes to conventional diesel operation, to support the development of cleaner, more efficient engines/fuel system.

\section{EXPERIMENTAL SETUP AND PROCEDURE}

\subsection{Engine and Fuel System}

Experiments were performed in a single-cylinder version of a heavy-duty engine modified to provide optical access to the combustion chamber. A schematic and the primary specifications of the engine are provided in Fig. 1 and Table 1, respectively. The main differences between the optical engine and a comparable production engine relate to the piston bowl, which has a flat bottom, vertical walls, and a larger land above the top 
compression ring. The larger top-ring land allows optical access through a notch in the piston bowl-rim and prevents the rings from riding over the cylinder-wall windows. The above differences lead to a lower geometric compression ratio (CR) of 12.3:1 for the optical engine versus $\sim 16: 1$ for a comparable production engine. To compensate for the lower $\mathrm{CR}$, the intake temperature and pressure are elevated to closely match the conditions in the production engine over the crank-angle range during which combustion occurs [22].

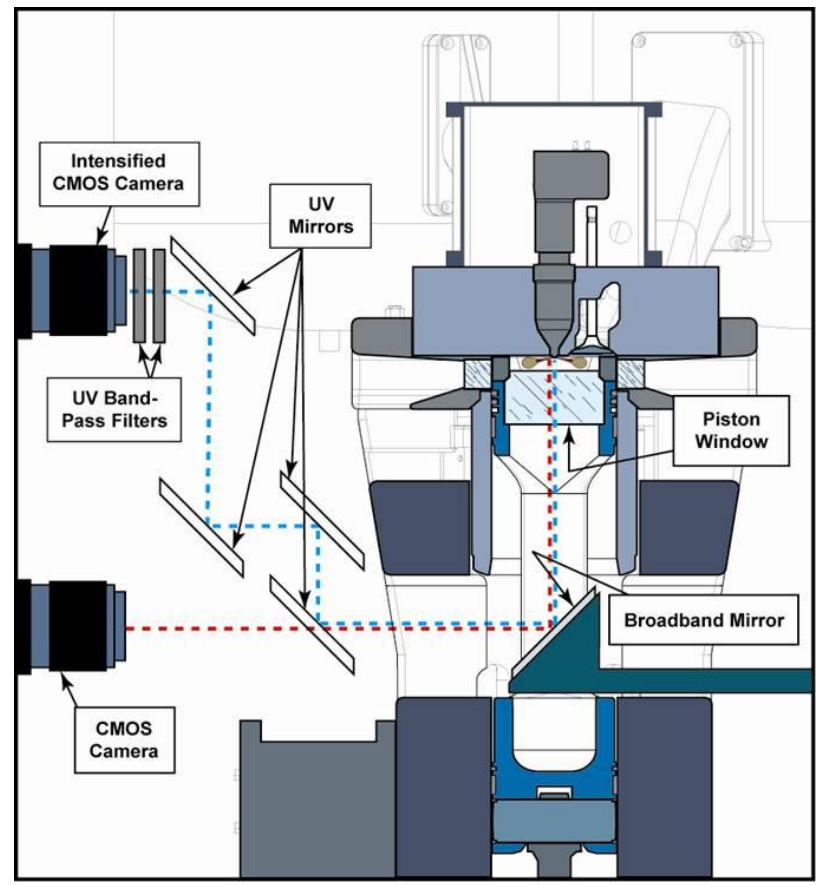

Figure 1. Optical engine schematic. Intensified and non-intensified cameras are used for chemiluminescence and natural luminosity imaging, respectively.

For these experiments the optical engine was skip-fired with one injection event every 5 engine cycles. This approach reduces the rate of soot accumulation on the combustionchamber windows and lowers the risk of window failure due to thermal and mechanical stresses generated when switching between motored and fired operation [7]. Skip-firing affects the exhaust-gas composition, thus real EGR was not used. Instead, EGR was simulated by adding $\mathrm{N}_{2}$ and $\mathrm{CO}_{2}$ to the dry intake air. A heater was used to maintain a constant coolant temperature because the heat rejection from the combustion chamber to the coolant is lower during skip-fired operation compared to a continuously fired mode.

Fuel delivery was accomplished using a prototype high-pressure common-rail fuel-supply system comprised of two modified diaphragm pumps (Newport Scientific, Model 46-16060), and a near-production Caterpillar electronically actuated solenoid-operated fuel injector fitted with a two-hole tip. The fuel-wetted internals of the pump are fabricated from Teflon, stainless steel, and Kalrez, making the system suitable for handling a wide range of conventional and unconventional fuels having high corrosivities, low viscosities, or other properties that can cause conventional piston-type pumps to fail. It is noted that TPGME does not present these challenges.

Fuel-injector specifications are provided in Table 2. X-ray tomography was used to confirm the orifice diameter, length-to-diameter ratio, and included spray angle listed in Table 2 (refer to [23] for typical injection-rate profiles for the 2-hole tip at injection pressures of $80 \mathrm{MPa}$ and $180 \mathrm{MPa}$, as measured using a momentum-based rate-of-injection meter developed at Sandia [24]). 
Table 1. Optical-engine specifications.

\begin{tabular}{ll}
\hline Research engine type & Single-cylinder \\
Cycle & 4 -stroke CIDI \\
Valves per cylinder & 4 \\
Bore & $125 \mathrm{~mm}$ \\
Stroke & $140 \mathrm{~mm}$ \\
Intake valve open $^{\mathrm{a}}$ & $32^{\circ}$ BTDC exhaust \\
Intake valve close $^{\mathrm{a}}$ & $153^{\circ}$ BTDC comp. \\
Exhaust valve open $^{\mathrm{a}}$ & $116^{\circ}$ ATDC comp. \\
Exhaust valve close $^{\mathrm{a}}$ & $11^{\circ}$ ATDC exhaust \\
Connecting-rod length & $225 \mathrm{~mm}$ \\
Connecting rod offset & None \\
Piston-bowl diameter & $90 \mathrm{~mm}$ \\
Piston-bowl depth & $16.4 \mathrm{~mm}$ \\
Squish height & $1.5 \mathrm{~mm}$ \\
Swirl ratio & 0.59 \\
Displacement & 1.72 liters \\
Compression ratio (geometric) & $12.3: 1$ \\
\hline
\end{tabular}

${ }^{\mathrm{a}}$ All valve timing are for $0.03 \mathrm{~mm}$ lift

${ }^{\mathrm{b}}$ Measured at the Caterpillar Technical Center using an AVL squirl meter

A flush-mounted, water-cooled pressure transducer (AVL Model QC32C) was used to measure cylinder pressure every 0.5 crank angle degree (CAD). Gas analyzers (California Analytical Instruments, Series 600) measured $\mathrm{CO}, \mathrm{CO}_{2}, \mathrm{O}_{2}, \mathrm{NO}_{\mathrm{x}}$, and $\mathrm{HC}$ emissions. A smoke meter (AVL Model 415S) and a prototype exhaust laser induced incandescence (LII) instrument [25] measured engine-out smoke/soot emissions. The procedures used for cylinder-pressure data acquisition and how the skip-fired exhaust-gas measurements were converted to values similar to those that would be obtained if the engine was operated in a continuous-fired mode are described in [26]. References [7, 22] provide further details of the experimental setup and procedures.

Table 2. Common-rail fuel-injector specifications.

\begin{tabular}{ll}
\hline Injector type & Cat CR350 \\
Injector tip style & Mini-sac \\
Injector tips & 2 -hole \\
Orifice diameter (nom.) & $110 \mu \mathrm{m}$ \\
Orifice L/D & 8 \\
Hydro-erosion & $20 \pm 2 \%$ \\
Included spray angle & $140^{\circ}$ \\
\hline
\end{tabular}

\subsection{Fuels}

The T50 test fuel was a 50/50 blend by volume of TPGME and the \#2 ultra-low-sulfur diesel emissions-certification fuel, Batch A, used in previous studies [7, 23, 27] and denoted $\mathrm{CF}$ herein. TPGME has an oxygen content of $31 \%$ by mass and is produced commercially as a mixture of up to eight isomers [28] by reacting propylene oxide with methanol [29]. It is used in the manufacture of polyester plastics and as a coupling agent or solvent for household 
and industrial cleaners such as oven cleaner. It is also used for rust, paint, and varnish removers, as a solvent for coil and wood coatings, and as a solvent for ballpoint, felt-tipped pens, and inkpads (to prevent drying). CF was also used as the baseline fuel. Selected properties of CF, TPGME, and T50 are presented in Table 3 (refer to [7] and [8] for detailed $\mathrm{CF}$ and TPGME properties, respectively). Because of its oxygen content, TPGME has a specific energy (energy per unit mass) that is $35.4 \%$ lower than the baseline fuel, but this effect is somewhat mitigated by blending it with $\mathrm{CF}$.

Table 3. Selected properties of the test fuels.

\begin{tabular}{lcccc} 
Parameter & Test Method & CF & TPGME & T50 \\
\hline Oxygenate volume fraction [\%] & & 0.0 & 100 & 50.0 \\
Stoichiometric air/fuel ratio, A// $\mathrm{F}_{\text {st }}[-]$ & & 14.5 & 13.1 & 13.8 \\
Oxygen ratio, $\Omega_{\mathrm{f}}[\%]$ & & 0.0 & 12.9 & 5.79 \\
Carbon [mass \%] & ASTM D5291 & 87.0 & 58.2 & 71.7 \\
Hydrogen [mass \%] & ASTM D5291 & 13.0 & 10.7 & 11.8 \\
Oxygen [mass \%] & ASTM D5291 & 0.0 & 31.0 & 16.5 \\
Specific gravity[-] & ASTM D4052 & 0.848 & 0.963 & 0.906 \\
Cetane number [-] & ASTM D613 & 43.3 & 65 & 55 \\
Net heat of combustion [MJ/kg] & ASTM D240 & 42.9 & 27.7 & 34.8 \\
\hline
\end{tabular}

The oxygen ratio of a fuel $\left(\Omega_{\mathrm{f}}\right)$ in Table 3 is defined as the amount of oxygen in the mixture divided by the amount of oxygen required to convert all fuel elements to $\mathrm{CO}_{2}$ and $\mathrm{H}_{2} \mathrm{O}[30]$ :

$$
\Omega_{f}=\frac{n_{O}}{2 n_{C}+\frac{1}{2} n_{H}}
$$

where $n_{O}, n_{C}$, and $n_{H}$ are the numbers of oxygen, carbon, and hydrogen atoms, respectively, in the fuel, and it is assumed that the fuel mixture does not initially contain $\mathrm{CO}_{2}$ or $\mathrm{H}_{2} \mathrm{O}$.

\subsection{Engine Operating Conditions}

Table 4 presents the engine operating conditions. The engine was fired (i.e., fuel was injected) once every $5^{\text {th }}$ cycle at $1500 \mathrm{rpm}$ for a minimum of 180 fired cycles per engine run. To ensure good data repeatability, at least 540 engine cycles of pressure-based data were recorded at each operating condition during three separate optical-engine runs that generally occurred on different days. As a result, data points presented in the figures throughout this paper represent averages over the three replicate measurements at the same test condition; error bars on Figs. 2 and 6 denote minimum and maximum observed values on those three separate optical-engine runs.

The experiments were performed at two injection pressures (80 $\mathrm{MPa}$ and $180 \mathrm{MPa})$, constant engine speed, intake pressure, and intake temperature. Three dilution levels $-21,18$, and $16 \mathrm{~mol} \% \mathrm{O}_{2}$-were studied to simulate the effects of using zero to moderate EGR rates. Table 5 shows the mole fractions of $\mathrm{O}_{2}, \mathrm{~N}_{2}, \mathrm{CO}_{2}$, and argon (Ar) in each intake mixture. Although the intake- $\mathrm{O}_{2}$ mole fraction $\left(\mathrm{X}_{\mathrm{O} 2}\right)$ varied, the gas-mixture compositions were selected so that the temperature, density, pressure, and specific heat at -10 CAD ATDC remained constant at roughly $850 \mathrm{~K}, 26 \mathrm{~kg} / \mathrm{m}^{3}, 63 \mathrm{bar}$, and $35 \mathrm{~J} / \mathrm{mol} / \mathrm{K}$, respectively. This approach was taken to isolate the effects of $\mathrm{X}_{\mathrm{O} 2}$ variation on the results and reduce the rate of consumption of bottled $\mathrm{CO}_{2}$ during experiments (real EGR contains higher $\mathrm{CO}_{2}$ levels). A 
mathematical modeling and problem solving software package (Universal Technical Systems, TK Solver) was employed to determine the mole fractions presented in Table 5.

Table 4. Selected engine operating parameters.

\begin{tabular}{ll} 
Description & Value \\
\hline Engine speed & $1500 \mathrm{rpm}$ \\
Intake manifold pressure & $250 \mathrm{kPa}$ \\
Intake manifold temperature & $95.0^{\circ} \mathrm{C}$ \\
Coolant temperature & $95^{\circ} \mathrm{C}$ \\
Fuel injection pressure & $80,180 \mathrm{MPa}$ \\
Intake oxygen & $21,18,16 \mathrm{~mol} \%$ \\
Injection duration (actual) & $3500 \mu \mathrm{s}$ \\
Start of combustion & $-5.0 \mathrm{CAD}$ ATDC \\
\hline
\end{tabular}

Table 5. Species mole fractions (X) and densities $(\rho)$ of the studied charge-gas mixtures.

\begin{tabular}{lccc} 
Parameter & $21 \mathrm{~mol} \% \mathrm{O}_{2}$ & $18 \mathrm{~mol} \% \mathrm{O}_{2}$ & $16 \mathrm{~mol} \% \mathrm{O}_{2}$ \\
\hline $\mathrm{X}_{\mathrm{O} 2}[\mathrm{~mol} \%]$ & 20.947 & 18 & 16 \\
$\mathrm{X}_{\mathrm{N} 2}[\mathrm{~mol} \mathrm{\%}]$ & 78.084 & 80.899 & 82.811 \\
$\mathrm{X}_{\mathrm{CO} 2}[\mathrm{~mol} \mathrm{\% ]}$ & 0.035 & 0.298 & 0.476 \\
$\mathrm{X}_{\mathrm{Ar}}[\mathrm{mol} \mathrm{\%}]$ & 0.934 & 0.803 & 0.713 \\
$\rho$ at $-10 \mathrm{CAD}$ ATDC $\left[\mathrm{kg} / \mathrm{m}^{3}\right]$ & 26.0 & 25.9 & 25.8 \\
\hline
\end{tabular}

Injection timing and injection duration were chosen to obtain predominantly mixingcontrolled combustion and valid lift-off length measurements. As indicated in Table 4, the start of combustion (SOC) also was held constant for all fuels and operating conditions. SOC was defined in this study as the crank angle where the high-temperature heat release first becomes positive after the start of injection. Table 6 shows that the similar injection duration for T50 and CF operation resulted in a 25\% load difference due to the lower T50 net heat of combustion (see Table 3).

Table 6. Engine load (gIMEP [bar]) as a function of fuel type and injection pressure.

\begin{tabular}{lcc} 
Injection Pressure & CF & T50 \\
\hline $80 \mathrm{MPa}$ & $1.72 \pm 0.03$ & $1.25 \pm 0.03$ \\
$180 \mathrm{MPa}$ & $2.91 \pm 0.03$ & $2.19 \pm 0.03$ \\
\hline
\end{tabular}

\subsection{Optical Diagnostics}

Two high-speed cameras were used to simultaneously record natural luminosity and $\mathrm{OH}^{*}$ chemiluminescence.

Natural luminosity (NL) refers to the broadband light emitted by the combustion process during a fired cycle and used to indicate the locations of high-temperature soot particles during mixing-controlled combustion [31]. In this study NL signal in the range of 380-1000 $\mathrm{nm}$ was collected every 0.5 CAD using a high-speed CMOS camera (Vision Research, Model Phantom v7.3) fitted with a $35-\mathrm{mm}$ Nikon lens. The combustion chamber is visualized from 
below through the fused-silica piston window using a $45^{\circ}$ mirror, as shown in Fig. 1 . The field of view is $104 \mathrm{~mm} \times 96 \mathrm{~mm}$ with a spatial resolution of $0.5 \mathrm{~mm} / \mathrm{pixel}$.

Spatially integrated natural luminosity (SINL) was determined at each CAD by summing the intensities of all pixels, corrected for aperture setting and image exposure:

$$
\operatorname{SINL}(C A D)=\frac{f_{s}^{2}}{t_{\text {exp }} S I N L_{\max }} \sum_{y=1}^{m} \sum_{x=1}^{n} N L(x, y, C A D)
$$

In Eq. 2, $n$ and $m$ are the number of pixels in the $x$-and $y$-directions, respectively; $f_{s}$ is the lens $f$-stop; and $t_{\text {exp }}$ is the image exposure duration. SINL $L_{\max }$ is the signal that would be measured if all pixels within the piston bowl were saturated when the lens aperture and exposure time were set to their minimum values (i.e., $f_{s}=16$ and $t_{\exp }=1.0 \mu \mathrm{s}$ ). SINL values provide a time-resolved, quantitative measure of high-temperature soot that can be compared between different engine runs. However, Eq. 2 shows that the constant aperture setting and image exposure used during a particular engine run limits the capability of the camera to capture the NL signal once the in-cylinder conditions decrease the soot temperature below the camera detection limit for that engine run (e.g., for images acquired near or after the end of combustion). Further details of the NL data-acquisition procedure can be found in [7].

Chemiluminescence (CL) signal from electronically excited hydroxyl radicals $\left(\mathrm{OH}^{*}\right)$ at $308 \pm 10 \mathrm{~nm}$ was used to determine the flame lift-off length $(\mathrm{H})$. The CL signal was collected every 1.0 CAD using an intensified CMOS camera (Vision Research, Model Phantom v311) and a Nikon 105-mm ultraviolet (UV) lens. A sequence of $114 \mathrm{~mm}$ x $114 \mathrm{~mm}$ images with a spatial resolution of $0.23 \mathrm{~mm} /$ pixel was captured during each fired cycle. CL images were analyzed following the procedure described in [7].

$\mathrm{H}$ measurements present inherent jet-to-jet and cycle-to-cycle variations, which are addressed by defining a mean value at each crank angle during the injection process, $\overline{H(C A D)}$ :

$$
\overline{H(C A D)}=\frac{1}{n_{\text {cycle }} n_{\text {jets }}} \sum_{c=1}^{n_{\text {cycle }}} \sum_{j=1}^{n_{\text {jets }}} H(j, c, C A D)
$$

In Eq. 3, $H(j, c, C A D)$ represents the lift-off length measurement from a single jet and cycle, at a specific crank-angle degree; $n_{\text {jets }}$ is the number of injector orifices, and $n_{\text {cycle }}$ is the number of engine cycles imaged. For notational simplicity, $\overline{H(C A D)}$ will be referred to as $\mathrm{H}$ in the rest of this paper.

Averaging the lift-off length over the total number of imaged cycles and injector jets can hide jet-to-jet variations, especially for operating conditions where $\phi(\mathrm{H})$ is close to the nonsooting limit $(\phi(H) \sim 2)$. In this case, one sooting jet $(\phi(H)>2)$ may be responsible for all of the soot production if $\phi(\mathrm{H})$ for the other jet is lower than the sooting limit. Nevertheless, the SINL data did not show any large cyclic variations from one jet to another in this work, and there were no outliers in soot emissions measurements when correlated to $\phi(\mathrm{H})$.

The equivalence ratio at the flame lift-off length, $\phi(\mathrm{H})$, has been shown to correlate with in-cylinder soot levels, with significant NL appearing only for $\phi(H)$ values greater than 2 [6]. The methodology used to calculate $\phi(\mathrm{H})$ in this study is based on Naber and Siebers' relationship [32]. Reference [23] details the methodology and discusses the validity of this approach in estimating $\phi(\mathrm{H})$ for the experimental setup used in this study.

\section{RESULTS}

\subsection{Soot}


Filter smoke numbers (FSN; measured with the AVL smoke meter and corrected for skipfiring) as a function of $\mathrm{X}_{\mathrm{O} 2}$ for the T50 and $\mathrm{CF}$ at the 180- and 80-MPa injection pressures are presented in Fig. 2. Independent of charge dilution, FSN values for T50 at both injection pressures are below $0.01 \mathrm{FSN}$, with the exception of the $80-\mathrm{MPa}, 16-\mathrm{mol} \% \mathrm{O}_{2}$ condition at which $\mathrm{FSN} \approx 0.03$.

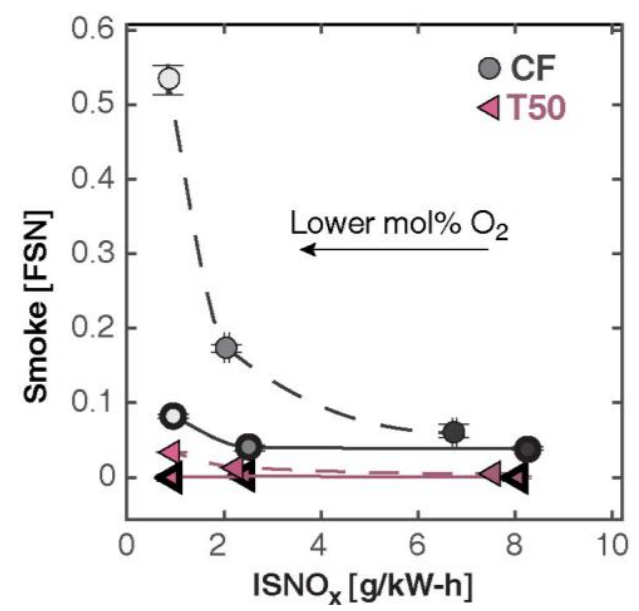

Figure 2. Fuel effects on smoke (FSN) and indicated-specific $\mathrm{NO}_{\mathrm{x}}$ emissions at $80 \mathrm{MPa}$ (dotted lines) and $180 \mathrm{MPa}$ fuel injection pressure (solid lines). Each marker represents the average of three replicates at a given condition, and error bars show the minimum and maximum values observed in each set of replicates.

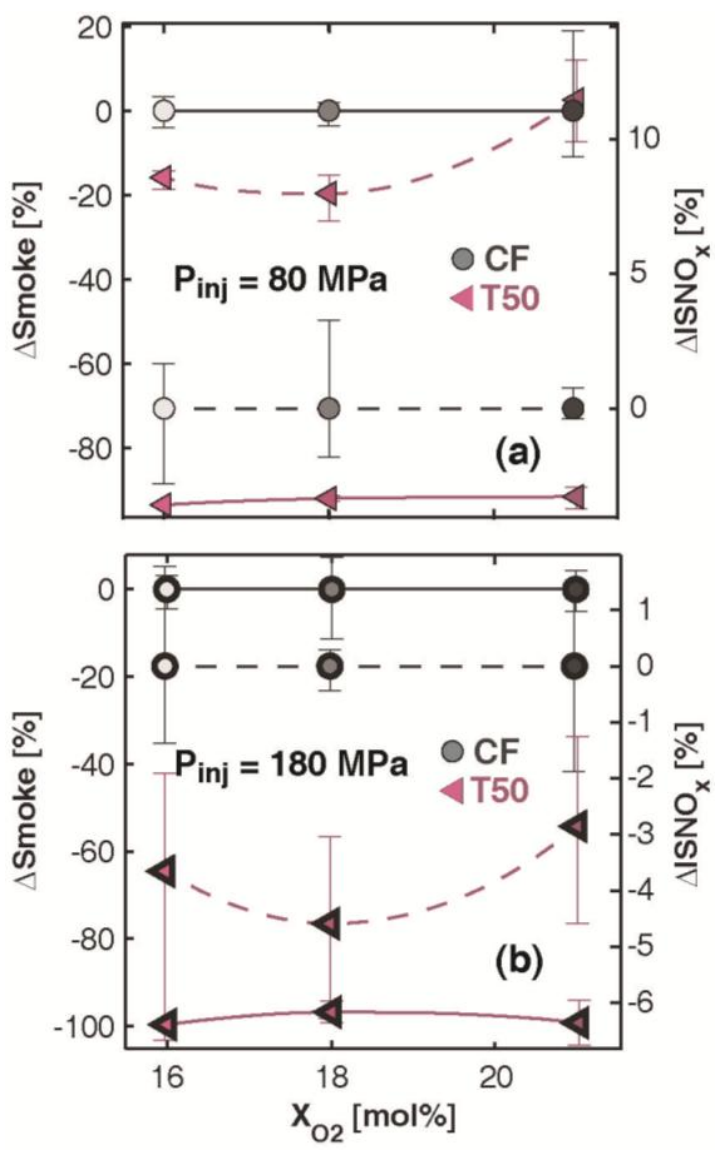

Figure 3. Change in T50 smoke emissions (FSN; left y-axis; solid lines) and indicatedspecific $\mathrm{NO}_{\mathrm{x}}$ emissions (right y-axis; dotted lines) relative to the baseline fuel at $80 \mathrm{MPa}$ (a) and $180 \mathrm{MPa}$ (b) fuel injection pressure. Each marker represents the average of three 
replicates at a given condition, and error bars show the minimum and maximum values observed in each set of replicates.

Figure 3 shows that engine-out smoke emissions for T50 were reduced by more than $80 \%$ at the $80-\mathrm{MPa}$ fuel injection pressure and effectively eliminated at the 180-MPa fuel injection pressure (i.e., FSN values below 0.002). Exhaust-LII measurements, not shown here, were in excellent agreement with the FSN results.

The lower engine-out smoke emissions for T50 operation were not the result of a change in the combustion mode to more-premixed conditions. The Apparent Heat Release Rate (AHRR) in Fig. 4 indicates a similar or smaller premixed-combustion fraction and similar CA50 (the engine crank angle corresponding to 50\% mass fraction burned) for T50 and CF at all conditions tested. In addition, none of the operating conditions in this study were limited by the availability of in-cylinder oxygen. Hence, the lower smoke level appears to be due to the effect of the oxygen content and/or fuel molecular structure. This is consistent with the effect of biodiesel on soot, with percent reductions that scale with and are more significant than the mass percent of fuel oxygen [33]. The study of Kurtz et al. [18] also shows the effects of a highly oxygenated fuel on engine-out emissions when it is used to fuel an engine designed and calibrated for conventional diesel fuel.
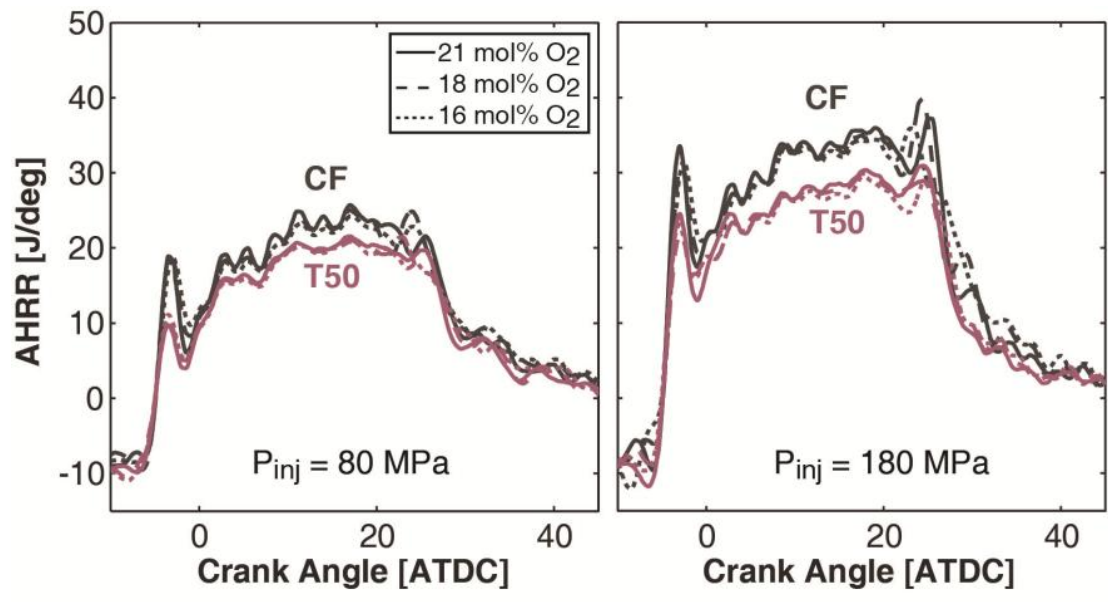

Figure 4. Apparent heat release rate (AHRR) for $80-\mathrm{MPa}$ and $180-\mathrm{MPa}$ injection pressure cases.

Even if T50 almost eliminated exhaust smoke emissions, combustion-image analysis showed soot incandescence in all cases, including those with effectively zero FSN. While not presented here, combustion images indicate that soot incandescence first appeared downstream of the lift-off length and continued expanding in the radial direction until it reached the piston-bowl rim and was subsequently redirected along the circumference of the bowl-rim inner diameter. NL intensity decreased gradually later in the cycle, but the magnitude of the decrease and its timing were fuel-dependent.

SINL helps to provide a better understanding of the processes that have led to the exceptionally low soot emissions with T50. CAD-resolved SINL values calculated with Eq. 2 and presented in Fig. 5 reveal that TPGME addition to the base fuel changes the SINL magnitude and its evolution, producing a lower signal than CF. For example, TPGME addition reduced the maximum SINL intensity by $\sim 40 \%$ at the $80-\mathrm{MPa}$ injection pressure and $21 \mathrm{~mol} \% \mathrm{O}_{2}$, and by $\sim 90 \%$ at the $180-\mathrm{MPa}$ injection pressure and $16 \mathrm{~mol} \% \mathrm{O}_{2}$. The T50 cases had shorter SINL durations, probably due to the reduced engine load and lower $\mathrm{A} / \mathrm{F}_{\mathrm{st}}$. Both fuels exhibited an almost-linear rise of SINL after the start of combustion, with a 
steeper and longer ramp at $80-\mathrm{MPa}$ fuel injection pressure. This soot-formation period occurred for approximately 5 CAD and 10-15 CAD after the first T50 and CF incandescence was observed, respectively. After that, $\mathrm{CF}$ had a very different in-cylinder soot evolution than T50. CF soot formation and soot oxidation more-or-less offset each other, creating a SINL "plateau" lasting from the end of the initial SINL rise until the end of injection (EOI). The irregular peaks in the CF SINL curves are probably associated with soot moving into and out of the squish volume, which is blocked from view by the piston-window retainer ring, rather than actual in-cylinder NL fluctuations. The SINL for CF dropped off sharply after EOI due to a combination of soot oxidation and rapid cooling of soot particles in the expansion stroke, which reduced soot luminosity below the camera detection limit at that particular operating condition (rather than soot no longer being present in the field of view). The shorter SINL durations and the more-steady decreases in SINL levels for T50 after reaching a maximum value contrast the SINL evolution for CF. Furthermore, the T50 SINL disappears before the end of combustion, suggesting a combination of curtailed soot production and increased soot oxidation during and after the end of fuel injection, thus the zero engine-out smoke emissions. The process is evident at $80-\mathrm{MPa}$ injection pressure and less clear at 180-MPa fuel injection pressure, possibly due to a larger effect of a spray-wall interaction that could increase the local equivalence ratio and boost soot formation (see the discussion in the lift-off length section).
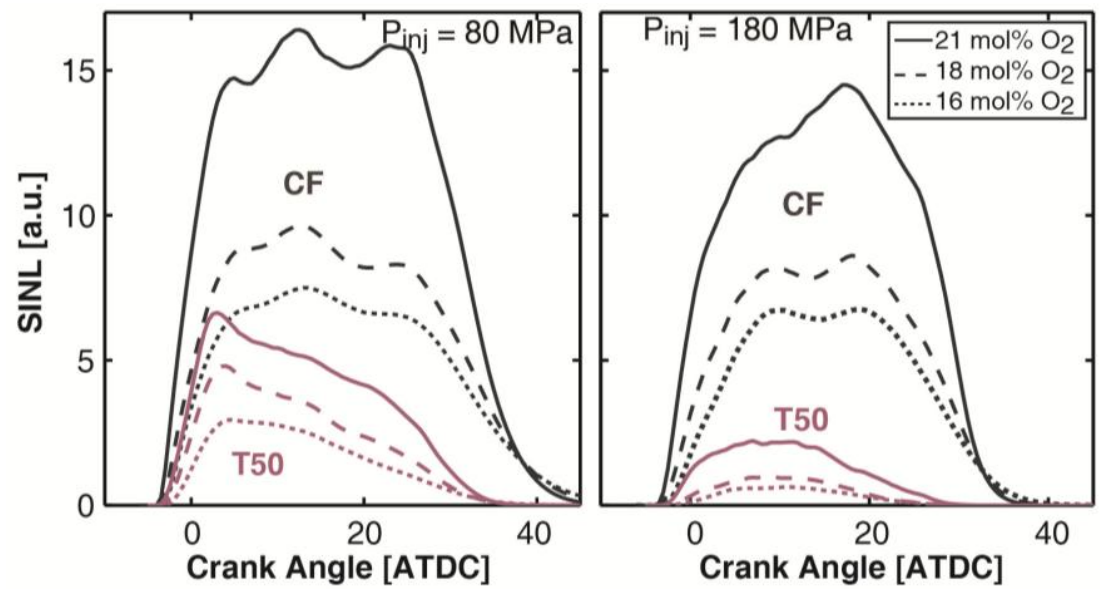

Figure 5. Spatially Integrated Natural Luminosity (SINL) for $80-\mathrm{MPa}$ and $180-\mathrm{MPa}$ injection pressure cases.

While the SINL signal levels are higher for both fuels at the $21-\mathrm{mol} \% \mathrm{O}_{2}$ conditions, the SINL drop-off slopes are larger, which combined with the lower engine-out smoke emissions 21-mol\% $\mathrm{O}_{2}$ suggests the following: (1) increased rates of oxidation during late-stage combustion compared with the 18- and 16- $\mathrm{mol} \% \mathrm{O}_{2}$ conditions; and (2) a larger fraction of soot escaping the reaction zone at higher dilution levels (and subsequently cooling down, thus the lower SINL levels, but higher smoke emissions).

\subsection{Indicated-specific $\mathrm{NO}_{\mathrm{x}}$ emissions.}

Figure 2 also shows that the decrease of in-cylinder oxygen content from 21 to $16 \mathrm{~mol} \% \mathrm{O}_{2}$ drastically lowered $\mathrm{ISNO}_{\mathrm{x}}$ emissions as well as the absolute differences between fuels. This is likely due to a decrease in $\mathrm{T}_{\mathrm{ad}}$ with decreasing $\mathrm{X}_{\mathrm{O} 2}$, as showed in ref. [23]. Further, Fig. 3 shows that the relative difference in $\mathrm{ISNO}_{\mathrm{x}}$ emissions between the two fuels was almost independent of charge dilution at a particular injection pressure. As thermal- $\mathrm{NO}_{\mathrm{x}}$ is the 
primary mechanism responsible for $\mathrm{NO}_{\mathrm{x}}$ emissions in diesel combustion, this result suggests that the dilution level had little effect on the relative difference in flame temperature and global in-cylinder temperature between fuels. The addition of TPGME affected $\mathrm{NO}_{\mathrm{x}}$ emissions, but the magnitude and direction of the effect changed with injection pressure. $\mathrm{NO}_{\mathrm{x}}$ emissions for T50 increased by $8-11 \%$ and decreased by 3-5\% at 80 and $180 \mathrm{MPa}$ injection pressure, respectively, compared with CF. However, TPGME addition also reduced the engine load by $25 \%$, which lowered in-cylinder temperature. Consequently, T50 could have higher ISNO $\mathrm{S}_{\mathrm{x}}$ emissions if the experiments were performed at constant load. Nevertheless, Fig. 2 shows that each fuel had a different effect on the change in $\mathrm{NO}_{\mathrm{x}}$ emissions with injection pressure at constant dilution. $\mathrm{NO}_{\mathrm{x}}$ emissions for $\mathrm{CF}$ increased by $12-23 \%$ compared with a $0-8 \%$ increase for T50, when the injection pressure changed from 80 to $180 \mathrm{MPa}$ (the lowest increase occurred at the highest dilution level, further supporting the importance of flame temperature on $\mathrm{NO}_{\mathrm{x}}$ emissions).

The different fuel effects on the change in $\mathrm{NO}_{\mathrm{x}}$ emissions with injection pressure at a particular dilution can presumably be explained by: (1) the less-effective fuel-to-air mixing at the lower injection pressure when the fuel-bound oxygen might increase the number and size of regions where combustion is closer to stoichiometric (and thus higher temperature) and/or increase atomic oxygen availability in $\mathrm{NO}_{\mathrm{x}}$ formation zones [34], (2) the slightly higher adiabatic flame temperature $\left(\mathrm{T}_{\mathrm{ad}}\right)$ of $\mathrm{CF}$ compared with $\mathrm{T} 50$ (see ref. [33] for the $\mathrm{C} / \mathrm{H}$ ratio effect on $\mathrm{T}_{\mathrm{ad}}$ ) at improved fuel-air mixing conditions at the higher injection pressure, and (3) the change in the ratio of premixed versus mixing-controlled combustion with injection pressure [33]. Notably, the conventional combustion smoke/ $\mathrm{NO}_{\mathrm{x}}$ trade-off was observed for $\mathrm{CF}$, but not for $\mathrm{T} 50$.

\subsection{Indicated-specific $\mathrm{HC}$ and $\mathrm{CO}$ emissions.}

Figure 6 indicates that ISHC emissions were higher for T50 compared to CF by $24-31 \%$ and $39-43 \%$, at 80 and $180 \mathrm{MPa}$ injection pressure, respectively. CO emissions had a similar trend, being higher for T50 compared to baseline fuel by 7-19\% and 32-44\%, at 80 and 180 MPa injection pressure, respectively. Higher ISHC and ISCO emissions for the T50 cases independent of injection pressure and charge dilution were likely the result of lower loads and lower in-cylinder temperatures for T50 which resulted from the lower net heat of combustion of T50 and the need to limit its fuel-injection duration to obtain valid lift-off length measurements. The lower in-cylinder temperatures with T50 likely inhibited HC and CO oxidation, leading to higher ISHC and ISCO emissions. At similar load and combustionphasing conditions, it is possible that the higher T50 reactivity due to its higher $\mathrm{CN}$ will increase $\mathrm{HC}$ and $\mathrm{CO}$ oxidation rates by avoiding the formation of over-lean, low-temperature combustion zones during pre-ignition and late combustion stages (considered responsible for the bulk of the $\mathrm{HC}$ and $\mathrm{CO}$ emissions), which may reduce the differences between fuels. 


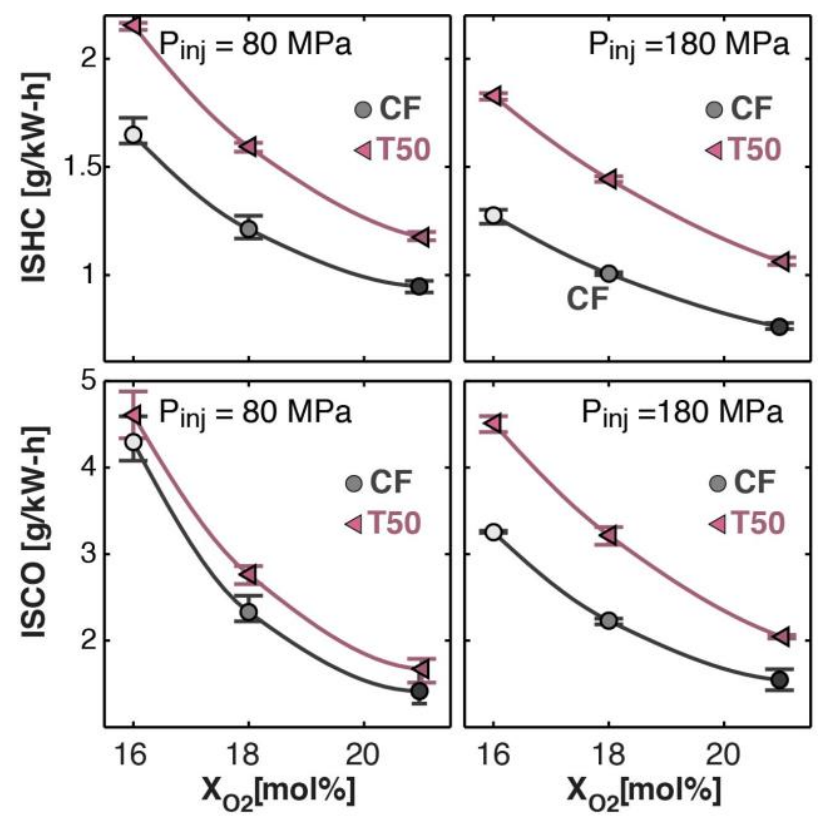

Figure 6. ISHC and ISCO emissions for $80-\mathrm{MPa}$ and 180-MPa injection pressure cases (triangles - T50, circles - CF). Each marker represents the average of three replicates at a given condition, and error bars show the minimum and maximum values observed in each set of replicates.

\subsection{Equivalence ratio at the flame lift-off length, $\phi(H)$}

Lift-off length $(\mathrm{H})$ measurements provide additional insights into soot formation for each of the fuels. Dec's conceptual model of conventional diesel combustion [35] suggests that as the fuel-rich premixed autoignition zone stabilizes at $\mathrm{H}$, near-stoichiometric combustion takes place in a diffusion flame surrounding the fuel jet. Although soot is generally formed on the rich side of the diffusion flame (i.e., toward the spray centerline), $\phi(\mathrm{H})$ is important because it dictates the temperature and composition of the fuel-rich partially reacted mixture downstream of $\mathrm{H}$ wherein soot precursors and soot are formed.

Higher injection pressure and higher charge dilution increase $\mathrm{H}$ due to higher spray velocity and longer ignition delay at lower $\mathrm{X}_{\mathrm{O} 2}$, respectively (ref. [23] contains more details on the effect of the operating condition on $\mathrm{H}$ for experimental conditions similar to the ones used in the current study). TPGME addition had almost no influence on $\mathrm{H}$ at a particular injection pressure or charge dilution other than to produce a small increase after 5-10 CAD ATDC, which could be due to the lower heat release seen in Fig. 4. Figure 7 shows that TPGME addition had an important effect on calculated $\phi(\mathrm{H})$. The reason is the lower stoichiometric ambient-gas to fuel mass ratio, $(\mathrm{A} / \mathrm{F})_{\mathrm{st}}$, for T50 regardless of the operating condition. As both fuels have similar densities and lift-off lengths, $\phi(\mathrm{H})$ depends mostly on $(\mathrm{A} / \mathrm{F})_{\mathrm{st}}[32]$. 

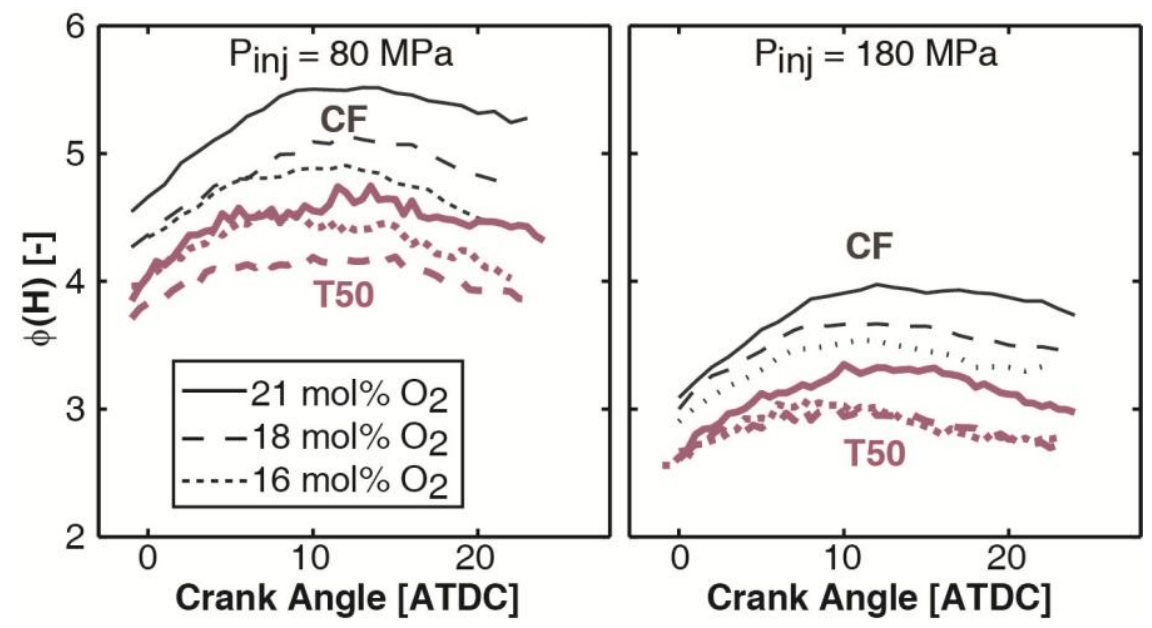

Figure 7. Equivalence ratio at lift-off length, $\phi(\mathrm{H})$ for $80-\mathrm{MPa}$ and $180-\mathrm{MPa}$ injection pressure cases.

Figure 7 can suggest that the reduction in $\phi(\mathrm{H})$ at lower intake- $\mathrm{O}_{2}$ may lower smoke emissions, which would seem to contradict the results presented in Fig. 2. In reality there is no contradiction because the lower soot formation associated with the decrease in $\phi(\mathrm{H})$ at a higher charge dilution is outweighed by the lower soot oxidation at those operating conditions, which is in agreement with the known $\mathrm{NO}_{\mathrm{x}}$-soot trade-off observed in conventional diesel combustion [36].

The differences in $\phi(\mathrm{H})$ help explain the differences in smoke emissions between T50 and $\mathrm{CF}$. At $80-\mathrm{MPa}$ injection pressure, T50 and CF had average $\phi(\mathrm{H})$ values in the range of 3.7-4.5 and 4.2-5.5, respectively, depending on charge dilution. $\phi(\mathrm{H})$ decreased substantially at 180-MPa injection pressure, with an average $\phi(\mathrm{H})$ for T50 and CF in the range of 2.5-3.3 and 2.9-4.0, respectively. The importance of keeping $\phi(\mathrm{H})$ closer to the non-sooting limit for low smoke emissions can be seen by comparing the smoke emissions and $\phi(\mathrm{H})$ variation with injection pressure, with FSN increasing up to an order of magnitude when the injection pressure decreased from 180 to $80 \mathrm{MPa}$, even though $\phi(\mathrm{H})$ increased by only $\sim 30 \%$. Regardless, the addition of TPGME to the base fuel did not result in LLFC conditions because $\phi(\mathrm{H})$ never reached the non-sooting limit of approximately 2 .

\section{SUMMARY AND CONCLUSIONS}

An optically accessible heavy-duty diesel engine was used to investigate the impact of tripropylene-glycol monomethyl ether (TPGME) on combustion and emissions. The objective was to determine if a 50/50 blend by volume of TPGME and ultra-low sulfur \#2 diesel certification fuel (CF), called T50, could enable LLFC compared with neat CF at similar incylinder conditions. The experiments were conducted at two fuel-injection pressures (80 and $180 \mathrm{MPa})$ and three levels of charge-gas dilution $\left(21,18\right.$, and $16 \mathrm{~mol} \% \mathrm{O}_{2}$ ). Diagnostics included conventional heat-release analysis, engine-out emissions, and high-speed simultaneous in-cylinder imaging of natural luminosity (NL) and $\mathrm{OH}$ chemiluminescence (CL). The major observations and conclusions of this study are:

- TPGME addition effectively eliminated engine-out smoke emissions by curtailed soot formation and/or increased soot oxidation during and after the end of fuel injection, compared to $\mathrm{CF}$. The oxygen content of the fuel affected smoke emissions more than the increase in injection pressure. 
- TPGME addition alone was insufficient to enable LLFC, with calculated equivalence ratios at the lift-off length, $\phi(\mathrm{H})$ larger than the non-sooting limit of $\sim 2$. As a result, soot incandescence was still visible at all operating conditions, albeit with a greatly reduced intensity for $\mathrm{T} 50$ relative to $\mathrm{CF}$.

- $\mathrm{ISNO}_{\mathrm{x}}$ emissions were lower for T50 relative to CF at the higher 180-MPa injection pressure, but higher at the lower $80-\mathrm{MPa}$ injection pressure. That injection pressure affected the influence of TPGME on $\mathrm{NO}_{\mathrm{x}}$ emissions is presumably related to the injection pressure effects on (1) the importance of fuel-bound oxygen with respect to the combustion temperature and/or atomic oxygen availability in $\mathrm{NO}_{\mathrm{x}}$ formation zones, (2) the importance of the change in the adiabatic flame temperature under conditions with improved fuel-to-air mixing, and (3) the ratio of premixed versus mixing-controlled combustion.

- ISHC and ISCO emissions were higher for T50 compared to the baseline fuel likely due to the lower loads and in-cylinder temperatures resulting from the lower net heat of combustion of T50 and the need to limit its fuel-injection duration for valid lift-off length measurements. Nevertheless, the differences in ISHC and ISCO emissions between the two fuels will probably decrease at similar engine load due to the higher T50 reactivity (i.e., higher $\mathrm{CN}$ ).

Despite the fact that TPGME addition could not enable LLFC under the operating conditions in this study, TPGME has the potential to achieve LLFC under different experimental conditions that would further decrease $\phi(\mathrm{H})$ to $\sim 2$ and below, such as a higher injection pressure and a lower intake temperature.

\section{AUTHOR INFORMATION}

\section{Corresponding author}

${ }^{\dagger}$ Address: West Virginia University, P.O. Box 6106, Morgantown, WV 26506, USA; email address: cosmin.dumitrescu@mail.wvu.edu

\section{Funding}

The experimental data were acquired while author Dumitrescu was employed by Sandia National Laboratories and funded by the U.S. Department of Energy (DOE). Preparation of this manuscript was performed while author Dumitrescu was employed and funded by West Virginia University.

\section{ACKNOWLEDGMENT}

This research was supported by the U.S. Department of Energy (DOE), Office of Vehicle Technologies. The authors gratefully acknowledge: DOE Office of Vehicle Technologies Program Manager Kevin Stork for long-term support of the optical-engine laboratory at Sandia; Bill Cannella of Chevron for providing the chemically and physically wellcharacterized \#2 ultralow-sulfur diesel emissions-certification fuel used in this work; and Sandia technologists Sam Fairbanks, Chris Carlen, and Gary Hubbard for their assistance with comprehensive/ mechanical, electronic, and data-acquisition hardware/software, respectively. The research was conducted at the Combustion Research Facility, Sandia National Laboratories, Livermore, California. Sandia is a multi-program laboratory operated by Sandia Corporation, a Lockheed Martin Company, for DOE's National Nuclear Security Administration under Contract DE-AC04-94AL85000.

\section{NOMENCLATURE}

ATDC After Top Dead Center 


$\begin{array}{ll}\text { AHRR } & \text { Apparent Heat Release Rate } \\ \text { BTDC } & \text { Before Top Dead Center } \\ \text { CA50 } & \text { CAD Corresponding to 50\% Mass Fraction Burned } \\ \text { CAD } & \text { Crank Angle Degree } \\ \text { CL } & \text { Chemiluminescence } \\ \text { CMOS } & \text { Complementary Metal Oxide Semiconductor } \\ \text { CN } & \text { Cetane Number } \\ \text { DOI } & \text { Duration of Injection } \\ \text { EGR } & \text { Exhaust-Gas Recirculation } \\ \text { EOI } & \text { End of Injection (Actual) } \\ \text { FSN } & \text { Filter Smoke Number (AVL) } \\ \text { H } & \text { Lift-Off Length } \\ \text { NL } & \text { Natural Luminosity } \\ \text { OH* } & \text { Electronically Excited Hydroxyl Radical } \\ \text { SINL } & \text { Spatially Integrated Natural Luminosity } \\ \text { SOC } & \text { Start of Combustion } \\ \text { A/F } & \text { Stoichiometric Air-to-Fuel Ratio } \\ \phi(H) & \text { Equivalence Ratio at Lift-off Length } \\ \Omega_{\mathrm{f}} & \text { Oxygen Ratio }\end{array}$

\section{REFERENCES}

[1] Zhao, F., Asmus, T. N., Assanis, D., Dec, J. E., Eng, J. A., and Najt, P. M., 2003, Homogeneous Charge Compression Ignition (HCCI) Engines: Key Research and Development Issues, Society of Automotive Engineers, Warrendale, PA.

[2] Kanda, T., Hakozaki, T., Uchimoto, T., Hatano, J., Kitayama, N., and Sono, H., 2005, "PCCI Operation with Early Injection of Conventional Diesel Fuel," SAE Trans. 114(3), pp. 584-593.

[3] Genzale, C. L., Reitz, R. D., and Musculus, M. P. B., 2008, "Effects of piston bowl geometry on mixture development and late-injection low-temperature combustion in a heavyduty diesel engine," SAE Int J Engines 1(1), pp. 913-937.

[4] Dumitrescu, C. E., Neill, W. S., Guo, H. S., Hosseini, V., and Chippior, W. L., 2012, "Fuel Property Effects on PCCI Combustion in a Heavy-Duty Diesel Engine," J. Eng. Gas Turbines Power, 134(5), p. 052801.

[5] Higgins, B., and Siebers, D., 2001, "Measurement of the Flame Lift-Off Location on D.I. Diesel Sprays Using OH Chemiluminescence," SAE Trans. 110(3), pp. 739-753.

[6] Pickett, L. M., and Siebers, D. L., 2004, "Non-Sooting, Low Flame Temperature MixingControlled DI Diesel Combustion," SAE Trans, 113(4), pp. 614-630.

[7] Polonowski, C. J., Mueller, C. J., Gehrke, C. R., Bazyn, T., Martin, G. C., and Lillo, P. M., 2011, "An Experimental Investigation of Low-Soot and Soot-Free Combustion Strategies in a Heavy-Duty, Single-Cylinder, Direct-Injection, Optical Diesel Engine," SAE Int. J. Fuels Lubr. 5(1), pp. 51-77.

[8] Natarajan, M., Frame, E., Naegeli, D. W., Asmus, T., Clark, W., Garbak, J., Gonzalez, M. A., Liney, E., Piel, W., and Wallace, J. P., 2001, "Oxygenates for advanced petroleum-based diesel fuels: Part 1. Screening and selection methodology for the oxygenates," SAE Trans. 110(4). 
[9] Gonzalez, M. A., Piel, W., Asmus, T., Clark, W., Garbak, J., Liney, E., Natarajan, M., Naegeli, D. W., Yost, D., Frame, E., and Wallace, J. P., 2001, "Oxygenates screening for advanced petroleum-based diesel fuels: Part 2. The effect of oxygenate blending compounds on exhaust emissions," SAE Trans. 110(4), pp. 2246-2255.

[10] Mueller, C. J., Pitz, W. J., Pickett, L. M., Martin, G. C., Siebers, D. L., and Westbrook, C. K., 2003, "Effects of oxygenates on soot processes in DI diesel engines: Experiments and numerical simulations," SAE Trans. 112(4), pp. 964-982.

[11] Akasaka, Y., Suzuki, T., and Sakurai, Y., 1997, "Exhaust Emissions of a DI Diesel Engine Fueled with Blends of Biodiesel and Low Sulfur Diesel Fuel," SAE Technical Paper Series, 972998.

[12] Manin, J., Skeen, S., Pickett, L., Kurtz, E., and Anderson, J. E., 2014, "Effects of Oxygenated Fuels on Combustion and Soot Formation/Oxidation Processes," SAE Int. J. Fuels Lubr. 7(3), pp. 704-717.

[13] Upatnieks, A., and Mueller, C. J., 2005, "Clean, controlled DI diesel combustion using dilute, cool charge gas and a short-ignition-delay, oxygenated fuel."

[14] Westbrook, C. K., Pitz, W. J., and Curran, H. J., 2006, "Chemical Kinetic Modeling Study of the Effects of Oxygenated Hydrocarbons on Soot Emissions from Diesel Engines," The Journal of Physical Chemistry A 110(21), pp. 6912-6922.

[15] Kook, S., Bae, C., Miles, P. C., Dae, C., and Pickett, L. M., 2005, "The Influence of Charge Dilution and Injection Timing on Low-Temperature Diesel Combustion and Emissions," SAE Technical Paper Series, 2005-01-3837.

[16] Kalghatgi, G., Risberg, P., and Angstrom, H.-E., 2006, "Advantages of Fuels with High Resistance to Autoignition in Late-Injection, Low-Temperature, Compression Ignition Combustion," SAE Technical Paper Series, 2006-01-3385.

[17] Torregrosa, A. J., Broatch, A., Novella, R., and Monico, L. F., 2011, "Suitability analysis of advanced diesel combustion concepts for emissions and noise control," Energy 36(2), pp. 825-838.

[18] Kurtz, E. M., Kuhel, D., Anderson, J. E., and Mueller, S. A., 2012, "A Comparison of Combustion and Emissions of Diesel Fuels and Oxygenated Fuels in a Modern DI Diesel Engine," SAE Int. J. Fuels Lubr. 5(3), pp. 1199-1215.

[19] Genzale, C. L., Pickett, L. M., and Kook, S., 2010, "Liquid Penetration of Diesel and Biodiesel Sprays at Late-Cycle Post-Injection Conditions," SAE Int. J. Engines 3(1), pp. 479495.

[20] Kashdan, J. T., Mendez, S., and Bruneaux, G., 2007, "On the origin of unburned hydrocarbon emissions in a wall-guided, low NOx diesel combustion system," SAE Trans. 116(4), pp. 234-257.

[21] Taylor, J., Li, H., and Neill, W. S., "Fuel Effects on Ignition and Their Impact on Advanced Combustion Engines," Proc. Diesel Engine-Efficiency and Emissions Research (DEER) ConferenceDetroit, MI, August 20-24, 2006.

[22] Fisher, B. T., and Mueller, C. J., 2010, "Liquid penetration length of heptamethylnonane and trimethylpentane under unsteady in-cylinder conditions," Fuel 89(10), pp. 2673-2696.

[23] Dumitrescu, C. E., Polonowski, C., Fisher, B. T., Cheng, A. S., Lilik, G. K., and Mueller, C. J., 2014, "An Experimental Study of Diesel-Fuel Property Effects on MixingControlled Combustion in a Heavy-Duty Optical CI Engine," SAE Int. J. Fuels Lubr. 7(1), pp. 65-81. 
[24] Kempenaar, J. G., Mueller, C. J., and Shollenberger, K. A., 2008, "An instrument for measuring orifice-specific fuel-injection rate from a multi-orifice nozzle (FEDSM 200855047)," ASME Fluids Engineering Division Summer MeetingJacksonville, FL.

[25] Axelsson, B., and Witze, P. O., 2001, "Qualitative laser-induced incandescence measurements of particulate emissions during transient operation of a TDI diesel engine," SAE Technical Paper Series, 2001-01-3574.

[26] Cheng, A. S., Upatnieks, A., and Mueller, C. J., 2007, "Investigation of fuel effects on dilute, mixing-controlled combustion in an optical direct-injection diesel engine," Energy Fuels 21(4), pp. 1989-2002.

[27] Mueller, C. J., Cannella, W. J., Bruno, T. J., Bunting, B., Dettman, H. D., Franz, J. A., Huber, M. L., Natarajan, M., Pitz, W. J., Ratcliff, M. A., and Wright, K., 2012, "Methodology for Formulating Diesel Surrogate Fuels with Accurate Compositional, Ignition-Quality, and Volatility Characteristics," Energy Fuels 26(6), pp. 3284-3303.

[28] Burke, U., Pitz, W. J., and Curran, H. J., 2015, "Experimental and kinetic modeling study of the shock tube ignition of a large oxygenated fuel: Tri-propylene glycol monomethyl ether," Combustion and Flame 162(7), pp. 2916-2927.

[29] 2010, "DOW' Product Safety Assessment Tripropylene Glycol Methyl Ether, available at http://www.dow.com/webapps/lit/litorder.asp?filepath=productsafety/pdfs/noreg/23300406.pdf\&pdf=true."

[30] Mueller, C. J., 2005, "The quantification of mixture stoichiometry when fuel molecules contain oxidizer elements or oxidizer molecules contain fuel elements," SAE Trans. 114(4), pp. 1243-1252.

[31] Mueller, C. J., and Martin, G. C., 2002, "Effects of oxygenated compounds on combustion and soot evolution in a DI diesel engine: Broadband natural luminosity imaging," SAE Trans. 111(4), pp. 518-537.

[32] Naber, J. D., and Siebers, D. L., 1996, "Effects of gas density and vaporization on penetration and dispersion of diesel sprays," SAE Trans. 105(3), pp. 82-111.

[33] Mueller, C. J., Boehman, A. L., and Martin, G. C., 2009, "An Experimental Investigation of the Origin of Increased NOx Emissions When Fueling a Heavy-Duty CompressionIgnition Engine with Soy Biodiesel," SAE Int. J. Fuels Lubr. 2(1), pp. 789-816.

[34] Cheng, A. S., Dumitrescu, C. E., and Mueller, C. J., 2014, "Investigation of Methyl Decanoate Combustion in an Optical Direct-Injection Diesel Engine," Energy \& Fuels 28(12), pp. 7689-7700.

[35] Dec, J. E., 1997, "A conceptual model of DI diesel combustion based on laser-sheet imaging," SAE Trans. 106(3), pp. 1319-1348.

[36] Heywood, J. B., 1988, Internal Combustion Engine Fundamentals, McGraw-Hill, New York. 